\title{
Isolation of selected possible aerobic bacterial pathogens from dental environmental surfaces after use of disinfectants - A case study at a public dental clinic, in KwaZulu-Natal
}

SADJ June 2020, Vol. 75 No. 5 p241 - p246

S Deulkar ${ }^{1}$, S Singh ${ }^{2}$, D Tiwari ${ }^{3}$

\section{ABSTRACT}

\section{Introduction}

Cross infection in the dental clinical environment remains a low priority in conversations around oral health care despite the high risk of exposure to blood and airborne infections.

\section{Aim and objectives}

The aim of this study was to determine the presence of selected pathogens after use of disinfectants on specific dental environmental surfaces at a public oral health facility in KwaZulu-Natal.

\section{Methods}

This was a cross-sectional descriptive case study with a non-experimental design. The dental clinical environment was divided into four zones and 9 dental units were systematically selected.

Swabs were collected from the 26 identified areas at specific time intervals $(7.00,9.00,11.00$, and 16.00) after the use of chlorine, ethanol $(70 \%$ in water) and glutaraldehyde (2\%) as surface disinfectants. The collected swab samples were cultured in nutrient agar media for two days at $37^{\circ} \mathrm{C}$. The colony forming units were then examined and characterized using the MALDI-TOF spectrometer

\section{Author affiliations:}

1. Swati Deulkar: BDS (Nagapur Nasik University), M.Sc (UKZN), Discipline of Dentistry, School of Health Sciences, University of KwaZulu-Natal, South Africa.

ORCID Number: 0000-0003-0842-9541

2. Shenuka Singh: B.OH, M.Sc (Dent), PhD (UWC), PG Dip Heal Res Ethics (Stell), Discipline of Dentistry, School of Health Sciences, University of KwaZulu-Natal, South Africa.

ORCID Number: 0000-0003-4842-602X

3. Dileep Tiwari: $P h D$ (Biotechnology) (University of Delhi), Discipline of Pharmaceutical Sciences, School of Health Sciences, University of KwaZulu-Natal, South Africa.

ORCID Number: 0000-0002-6342-1289

Corresponding author: Shenuka Singh

Associate Professor: Discipline of Dentistry, School of Health Sciences, University of KwaZulu-Natal, Private Bag X54001, Durban, South Africa.

Email: singhshen@ukzn.ac.za

Author contributions:

1. Swati Deulkar: First author - $65 \%$

2. Shenuka Singh: Second author $-25 \%$

3. Dileep Tiwari: Third author - 10\%

\section{Results}

Out of the 312 samples taken, 262 (84\%) were shown to be bacterial culture positive. The most contaminated areas in the dental environment were around the chair area (86.53\%) and the area away from the chair (92\%).

Glutaraldehyde was found to be more effective than chlorine and ethanol.

\section{Conclusion}

The study suggests an association between the frequency of cleaning, the type of disinfectant used and the bacterial microbial count on the specified dental environmental surfaces at the identified oral health facility.

\section{Keywords}

Infection control, disinfectants, dental environment, bacteria, cross-infection (contamination).

\section{INTRODUCTION}

Cross-contamination in the dental clinical environment should be a major public health concern given the high risk of exposure to blood and airborne infections however this remains a low priority in conversations around oral health care.

The greatest potential for cross-infection is among dental operators, assistants and patients, due to the presence of a combination of blood, saliva and contaminated instruments. ${ }^{1}$ Apart from these possible sources of cross contamination, the environmental work surfaces and water lines of dental units could pose a potential risk unless optimal infection control measures are in place. ${ }^{2}$

Patients have the right to access oral health care in a safe and healthy clinical environment. ${ }^{3}$ Universal precautions in infection control include hand washing/disinfection; use of personnel protective equipment (e.g. gowns, protective eye wear, and gloves); use of disinfectants for clinic surface cleaning; and appropriate handling and disposal of contaminated sharp instruments and other clinical waste. ${ }^{4,5}$ 
Ideally all vegetative microbes should be destroyed using heat sterilization procedures, however, it is neither cost effective nor practical to sterilize dental working surfaces or instruments that are heat sensitive. ${ }^{6}$ Disinfection provides a more practical solution for ensuring prevention of cross contamination. ${ }^{1}$ Disinfection is characterized by killing, destroying or removal of all pathogenic microbes, except spores. ${ }^{6,7}$

There are various disinfection methods, which include physical disinfection, heating and chemical disinfection. ${ }^{8}$ The disinfectants used in most hospital settings include aldehyde, alcohol, lodophors, quaternary ammonium compounds, alcohol ammonium and peroxygenated compounds. ${ }^{9}$ The effectiveness of a disinfection solution is dependent on factors such as the type of microbes present, the concentration of the chemical used, and its exposure time to the affected microbes. ${ }^{10}$

Environmental surfaces are classified as clinical (medical) contact and housekeeping surfaces. ${ }^{11}$ Clinical contact surfaces are those that comes in contact with contaminated devices, instruments, hands, or gloves, while housekeeping surfaces are not touched directly during the delivery of dental care. ${ }^{11}$ Damp dusting is a common disinfection procedure in the dental clinical environment. ${ }^{12}$ This study arose of the need to investigate the effectiveness of commonly used surface disinfectants on dental environmental surfaces. There is paucity of published literature that specifically examined the efficacy or effectiveness of commonly used surface disinfectants in oral health clinical settings in South Africa. ${ }^{13}$ The aim of this study was thus to determine the presence of selected pathogens after use of disinfectants on specific dental environmental surfaces at a public oral health facility in KwaZulu-Natal.

\section{METHODS}

This was a cross-sectional descriptive case study using a non-experimental design. Ethical clearance was obtained from the UKZN Biomedical Research Ethics Committee (BREC reference number: 068/16) and the KZN Department of Health.

(Reference number: 26/16 KZ-2015RP12-306).

\section{Areas of sampling}

Systematic random sampling was used to select 9 dental units for the study. All dental units in the oral health facility $(n=17)$ were considered and those numbered: $1,3,5,7,9,11,13,15,17$ were selected for the study. The dental clinical environment was divided into four zones:

1. Working area around the dental operator/assistant (chair head rest, arm rest, foot rest, dental hand pieces, overhead light source, air water syringe tip, spittoon, suction hose, base of dental chair, dental chair, foot pedal/control, instrument counter and handle).

2. Area behind the dental chair (wash basin, window, wall, table top, dust bin, taps).

3. Area away from the dental chair (computer processing unit, computer monitor, telephone, floor).

4. Reception area (patient chairs, reception table top).
All of these areas added up to 26 surfaces that were sampled at each of the nine units. Swabs were collected from the identified areas at 7.00 in the morning prior to the normal infection control and cleaning procedures that are conducted in the clinic (pre-disinfection).

\section{Disinfectants used}

Disinfectants such as Chlorine, ethanol (70\% in water) and Glutaraldehyde (2\%) were applied respectively as indicated below.

\section{Day 1: Chlorine:}

Chair 1: 26 swabs at 7.00 am after cleaning and at $9.00 \mathrm{am}$.

Chair 3: 26 swabs at $11.00 \mathrm{am}$.

Chair 5: 26 swabs at $16.00 \mathrm{pm}$.

\section{Day 2: Ethanol:}

Chair 7: 26 swabs at 7.00 am after cleaning and at $9.00 \mathrm{am}$.

Chair 9: 26 swabs at $11.00 \mathrm{am}$.

Chair 11: 26 swabs at $16.00 \mathrm{pm}$.

\section{Day 3: Glutaraldehyde}

Chair 13: 26 swabs at 7.00 am after cleaning and at $9.00 \mathrm{am}$.

Chair 15: 26 swabs at $11.00 \mathrm{am}$.

Chair 17: 26 swabs at 16.00 pm.

This was done by using a spray method, as per the manufacturer's instructions on the 26 sites and wiped with a cloth for one minute. The procedure of obtaining the swab samples was done by dipping cotton tipped swabs in sterile water using hand-held applicators (Sterilin, England), which were pre-moistened with sterile normal saline. These applicators were gently agitated/ rotated over the desired environmental surface.

A pilot study was conducted on dental units that were not a part of the identified clinical area so as to address any challenges in the data collection process.

\section{Procedure for culture growth and assessment}

The swabs were stored below $23^{\circ} \mathrm{C}$, after which they were taken to the microbiology laboratory for plating on nutrient agar and incubated at $37^{\circ} \mathrm{C}$ for 24 hours to enable microbial growth.

Colony forming unit (C.F.U.) counts on plates were checked for the highest number of different colonies after use of the disinfectant. This resulted in 104 swabs being collected after use of one disinfectant, with a total of 312 swabs for the three disinfectants.

The microbial colonies were differentiated by observation and sub-culturing was done either in bacterial or fungal species and other criteria such as growth on the specific growth media used, in addition to the MALDI TOF (Becton Dickinson Diagnostic Instrument System, Sparks, MD). All bacterial isolates were stored at very low temperature i.e. at $-80^{\circ} \mathrm{C}$ in Trypticase soy broth with $10 \%$ glycerol and recovered at $37^{\circ} \mathrm{C}$ in Nutrient Agar medium prior to use. 
Primary subcultures were used for MALDI-TOF MS analysis. The mass spectra were deposited in triplicate batches for each new strain. The same experiment was repeated the following day to ensure reliability of the test. A main spectrum (MSP) of the standard control strain was created to ensure correct identification of all peaks between the genera and the recommended score of 2.9 was used as the ideal detection score for the genus and species detection.

\section{Microbiological analysis}

The first step of the analysis involved visual assessment of the colonies on the agar plates. This involved identifying the morphology of the different bacterial growths and the presence of C.F.U counts. The second step of the analysis involved sub-culturing of a specific CFU colony. The colony with the highest healthy C.F.U. count was selected for sub-culturing.

The identified colony was picked up using the tip of a toothpick. Subculture colonies were grown on selective media such as MacConkey agar for Gram-negative bacteria. S. aureus was isolated using Manitol salt agar. Enterobacter species was isolated using Bile salt agar. The third step of the analysis was the species identification of the unknown isolates through the use of MALDI Biotyping.

The bacterial growth in the samples was checked before the application of the disinfectant, and this became the control measurement. This data was compared with the four selected areas (chair side area, area behind chair, area away from chair and reception area).

The colonial growth on the MALDI-TOF machine was checked and compared with the experimental bacterial spectra with the regulator group spectral bacteria (Bruker Bacterial Test Standard (BTS) and E. coli DH5 alpha). The microbial count was determined and compared after use of disinfectant at a specific time interval (the 7.00 am data was compared to the 11.00 am results).

The viable colony forming unit count (C.F.U.) in the range of 10 to 100 was considered to create infection. The key quality assurance process was the identification of each colony forming unit's molecular mass which was then compared to the bio-information repositories in MALDI-TOF.

\section{Statistical Analysis}

Univariate descriptive statistics such as frequency and mean distribution were conducted for all variables. An inferential technique such as the Pearson chi-squared test was used to determine a relationship between the use of the specified disinfectants and positive bacterial growth. A level of $\mathrm{p}<0.05$ was established as being statistically significant.

\section{RESULTS}

Types of pathogens identified in dental clinic

Altogether 312 swabs samples were collected from various sites and 262 samples (84\%) were found to be cul- ture positive. Almost ten different species of bacteria and fungi were isolated, with Staphylococcus and Bacillus spp being the most commonly isolated.

The most frequently isolated bacteria were Gram-positive cocci (CoNS, Enterococcus spp and S. aureus), and Gram-negative enteric bacilli (Escherichia coli and Klebsiella pneumoniae). Other strains such as Bacillus megaterium, Neisseria species and Enterobacter cloacae were confirmed by the MALDI-TOF.

In total, 78 samples were taken pre-disinfection and all samples (100\%) showed bacterial growth. After use of chlorine 68 samples out of 78 (87\%) showed bacterial growth. Six different bacterial strains were observed (Staphylococcus, Bacillus Enterococcus spp, S. aureus, Escherichia coli and Klebsiella pneumoniae).

After the use of ethanol, 61 samples out of 78 (78\%) showed bacterial growth and two different bacterial strains were observed (Bacillus and Staphylococcus species). After the use of Glutaraldehyde, 53 samples out of 78 (68\%) showed bacterial growth and only one bacterial strain was observed (Staphylococcus species).

\section{Most contaminated areas of the dental clinic post-disinfection}

The contaminated areas in the dental clinical environment included the working area around the dental operator/assistant where 135 out of 156 samples (86.5\%) had positive bacterial growth. This was followed by the area behind the chair where 59 out of 84 (70.2\%) had positive bacterial growth. Alarmingly, the area away from the dental chair had higher levels of positive bacterial growth (92\%).

The microbial count (CF.U.) for the identified areas of the dental clinic are presented in Table 1. The microbial count in the reception area before the application of disinfectants was high, and remained high despite the application of disinfectant at different time periods in the day. All samples in the reception area $(n=24 ; 100 \%)$ showed positive bacterial growth, which suggested that the reception area was more contaminated than the dental operating area.

\section{Level of contamination at different time intervals}

The percentages of microorganism growth after disinfection procedures at specific time intervals are indicated in Table 2. Glutaraldehyde was the most effective disinfectant at all tested times (mean=17.66, $p=0.01$ ) followed by Ethanol (mean=20.33). Chlorine was the least effective at all tested times (mean=22.66).

\section{DISCUSSION}

The results of this study indicated that the microbial count on dental environmental surfaces (pre and post disinfection) was fairly high. Staphylococcus species were found on various surfaces of the dental clinic.

These findings are in contrast with Umar et al. who reported that Staphylococcus aureus and coagulasenegative Staphylococcus (CONS) constituted only $6 \%$ and $5 \%$ respectively of their isolated bacterial strains. ${ }^{14}$ 
Although this study focused on surface microbial count, these findings are similar to those reported in studies that examined airborne microbial load within the dental operating area. ${ }^{15,16}$ The use of high-speed dental hand pieces (including those combined with a water spray) could potentially create aerosols which could increase risk for cross infection in the dental clinic. ${ }^{17,18}$ The presence of Staphylococcus species in this study could be attributed to its presence in the human body and it may suggest poor hand hygiene procedures or disinfection procedures. ${ }^{19}$ Mehtar et al. further observed in their study that infection control practices were sub-optimal despite the availability of related information on universal precautions for dental personnel. ${ }^{20}$

This study findings also indicated that colonies of Escherichia coli and Klebsiella pneumoniae species were isolated. This is consistent with Umar et al. who reported that almost $40 \%$ of their study samples were contaminated by bacterial colonization and included nosocomial species such as Staphylococcus aureus, Klebsiella pneumonia, and Enterococcus species. ${ }^{14}$

The authors suggested that use of mobile phones by dental practitioners in the clinical environment could be responsible for the spread of these nosocomial pathogens. ${ }^{14}$ The fact that these microorganisms can survive in the hospital environment increases the risk of cross infection in immuno-compromised and other patients. ${ }^{21}$ Additionally Molepo et al. reported Escherichia coli as the least commonly isolated organism present in their study post dental treatment while coagulase-negative staphylococci (84\%) was most predominant microorganism found on contaminated dental bib chains. ${ }^{22}$

Laheij et al. pointed out that more research is required to assess risks of cross infection associated with viral and bacterial infections in dental settings. ${ }^{23}$ However Kannan

\begin{tabular}{|c|c|c|c|c|c|c|c|c|c|c|c|c|}
\hline \multirow[b]{2}{*}{ Area/Time } & \multicolumn{4}{|c|}{ Chlorine } & \multicolumn{4}{|c|}{ Ethanol } & \multicolumn{4}{|c|}{ Glutaraldehyde } \\
\hline & 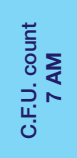 & 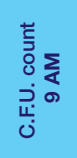 & 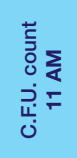 & 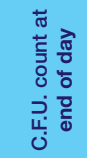 & 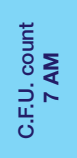 & 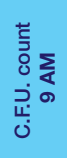 & 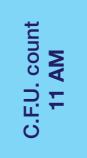 & 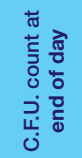 & 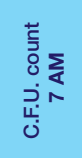 & 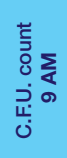 & 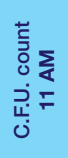 & 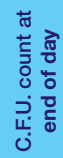 \\
\hline \multicolumn{13}{|c|}{ Chair side area: 135 out of 156 samples $(86.5 \%)$ positive for bacterial growth } \\
\hline Head rest & 20 & 60 & 30 & 60 & 50 & 20 & 30 & 50 & $>100$ & 1 & 50 & 50 \\
\hline Arm rest & 30 & 25 & $>100$ & 25 & 40 & 10 & $>100$ & 70 & 10 & 50 & 50 & 50 \\
\hline Foot rest & 20 & 100 & $>100$ & $>100$ & 25 & 25 & $>100$ & 90 & 20 & 0 & 50 & 50 \\
\hline Air-rotor & 25 & 0 & 40 & 20 & 40 & 0 & 0 & 20 & 50 & 0 & 0 & 3 \\
\hline Light source & 3 & 0 & 4 & 40 & 3 & 0 & 60 & 20 & 3 & 5 & 50 & 10 \\
\hline Air water syringe tip & 1 & 0 & $>100$ & 40 & 3 & 0 & 50 & 60 & 20 & 0 & 20 & 5 \\
\hline Spittoon & 20 & 20 & 60 & 20 & 30 & 30 & 0 & 30 & 100 & 10 & 50 & 60 \\
\hline Counter top & 20 & $>100$ & 0 & 10 & 30 & 0 & 0 & 30 & 10 & 0 & 0 & 0 \\
\hline Suction hose & $>100$ & 0 & 0 & $>100$ & $>100$ & 0 & 20 & $>100$ & 50 & 0 & 20 & 50 \\
\hline Chair base & 30 & $>100$ & 10 & 20 & 30 & 30 & $>100$ & 50 & 50 & 50 & 10 & 20 \\
\hline Dental stool & 30 & 20 & 15 & 30 & 30 & 25 & 20 & 20 & 50 & 10 & 0 & 10 \\
\hline Foot controller & $>100$ & 30 & 70 & $>100$ & $>100$ & 20 & 60 & $>100$ & $>100$ & 25 & 20 & 50 \\
\hline Handle & 4 & $>100$ & 10 & 16 & 4 & 30 & 30 & 30 & 40 & 0 & 0 & 10 \\
\hline \multicolumn{13}{|c|}{ Area behind chair: 59 out of 84 samples $(70.23 \%)$ positive for bacterial growth } \\
\hline Wash basin & 25 & 50 & 50 & 50 & 30 & 40 & 20 & 30 & 10 & 4 & 10 & 20 \\
\hline Window & 20 & 0 & 0 & 0 & 24 & 0 & 0 & 30 & 30 & 0 & 0 & 0 \\
\hline Wall & 2 & 5 & 9 & 5 & 2 & 0 & 0 & 5 & 28 & 0 & - & 50 \\
\hline Table top & 4 & 20 & 10 & 20 & 6 & 0 & $>100$ & 30 & 50 & 3 & - & 10 \\
\hline Dust bin & $>100$ & 20 & $>100$ & 20 & $>100$ & 0 & $>100$ & 90 & 20 & - & 5 & 50 \\
\hline Tap & 20 & 5 & $>100$ & 5 & 30 & 0 & 0 & 50 & 50 & 0 & 0 & 10 \\
\hline \multicolumn{13}{|c|}{ Area away from chair: 44 out of 48 samples $(92 \%)$ positive for bacterial growth } \\
\hline CPU & 30 & 40 & $>100$ & 40 & 36 & 0 & 10 & 30 & $>100$ & 0 & 5 & 5 \\
\hline Computer Screen & 50 & 30 & $>100$ & 30 & 50 & 0 & 10 & 20 & 50 & 0 & 0 & 0 \\
\hline Telephone & 70 & 15 & 3 & 5 & 50 & 10 & 10 & 20 & 50 & - & 5 & 50 \\
\hline Floor & $>100$ & 150 & $>100$ & 150 & $>100$ & 100 & $>100$ & $>100$ & 70 & 10 & 50 & 50 \\
\hline \multicolumn{13}{|c|}{ Reception area: All samples $(24,100 \%)$ positive for bacterial growth } \\
\hline Chair & $>100$ & 40 & 80 & $>100$ & $>100$ & 10 & 60 & $>100$ & 100 & 50 & 60 & 100 \\
\hline Reception table top & 20 & 20 & 60 & $>100$ & 20 & 12 & 50 & $>100$ & $>100$ & 60 & 100 & 60 \\
\hline \multicolumn{3}{|c|}{ Frequency of disinfection } & \multicolumn{3}{|c|}{ Chlorine } & \multicolumn{4}{|c|}{$70 \%$ Ethanol } & \multicolumn{3}{|c|}{$2 \%$ Glutaraldehyde } \\
\hline \multicolumn{3}{|c|}{7.00 am (pre-disinfection) } & \multicolumn{3}{|c|}{$26(100 \%)$} & \multicolumn{4}{|c|}{$26(100 \%)$} & \multicolumn{3}{|c|}{$26(100 \%)$} \\
\hline \multicolumn{3}{|l|}{$9.00 \mathrm{am}$} & \multicolumn{3}{|c|}{$21(80 \%)$} & \multicolumn{4}{|c|}{$15(56 \%)$} & \multicolumn{3}{|c|}{$13(52 \%)$} \\
\hline \multicolumn{3}{|l|}{$11.00 \mathrm{am}$} & \multicolumn{3}{|c|}{$23(88 \%)$} & \multicolumn{3}{|c|}{$21(80 \%)$} & & \multicolumn{3}{|c|}{$19(74 \%)$} \\
\hline \multicolumn{3}{|c|}{ $\pm 16.00 \mathrm{pm}$ (end of the working day) } & & $24(92 \%$ & & & 25 ( & \%) & & & (82\%) & \\
\hline
\end{tabular}


et al. postulate that aerobic and anaerobic spores will exist in the dental clinic despite stringent disinfection procedures. ${ }^{24}$ Thus more research is required to isolate the various microbial strains that could contaminate the dental workplace.

\section{Effectiveness of disinfectants}

Glutaraldehyde and ethanol had more effect on the identified in vitro bacteria. Glutaraldehyde appeared to control most of the bacteria, except staphylococcus species. These findings are consistent with Almeida et al., who reported that $2 \%$ glutaraldehyde was the only efficient method in their study to control microbial growth on orthodontic pliers when compared to ethyl alcohol $70 \%$ or soap and water. ${ }^{25}$

Ethanol also controlled most of the bacteria, except Bacillus and staphylococcus. ${ }^{26,27}$ Ethanol could therefore be a low-level or intermediate surface disinfectant. This finding is supported by Ribeiro et al. who reported that 'disinfection of semi-critical products (such as mouth mirrors and amalgam condensers) with alcohol $70 \%$, or in an approximate concentration, may be reached for both products that are previously cleaned and for the ones which are not. ${ }^{28: 750}$

Chlorine ${ }^{\circledR}$ was not active against many bacteria, since six different bacterial species were isolated, which was higher than ethanol and glutaraldehyde. Chlorine can thus be considered the weaker disinfectant for bacteria, with its possible resistance being attributed to its prolonged use in the hospital.

Although there is much debate around the efficacy of Chlorine $\AA$ as a disinfectant, a recent study concluded that surface cleaning with $0.5 \%$ chlorine solutions (using a 15-min exposure time) could be effective in reducing risk of viral transmission. ${ }^{29}$

Thus the selection of a disinfectant must include other factors such as its toxicity, chemical content, stability, cost, degree of microbial killing required, potential damage to instrument and ability to kill microorganisms rapidly. ${ }^{30}$ More research is required to further unpack these other considerations.

\section{Awareness of disinfection procedures in the dental clinic}

In this study, almost $87 \%$ of clinical surfaces were contaminated. It should be noted that the area around the chair had high levels of contamination levels despite the existing infection control procedures.

This finding is supported by Castalia et al. who also observed high levels of microbial load at the beginning of the working day. ${ }^{31}$

This study findings indicate that disinfection processes at the identified oral health facility is inadequate, suboptimal and could actually be contributing to the infection chain. There is an urgent need to review the current infection control procedures and protocols, including a review of the type of surface disinfectants used.
The frequency of disinfection (damp-dusting and housekeeping) should be reviewed, given the number of patients seen at the facility. It is also imperative that simple procedures such as awareness of hand hygiene practices are implemented and prioritized. In addition, there should be dedicated infection control monitoring and evaluation processes.

Although the study provided interesting insights into the comparative effectiveness of surface disinfectants against identified bacterial growth, some limitations were noted. The study focused only on bacteria that were identified on the MADI-TOF database.

The study did not investigate any other resistant strains of bacteria. The use of blood agar media to support in vitro pathogenic bacterial growth could be explored in future studies. ${ }^{32}$ The study also focused exclusively on bacteria and did not investigate other microbes that could contribute to the cross-infection chain. More research is needed to explore this relationship further.

\section{CONCLUSION}

The study suggests an association between the frequency of cleaning, the type of disinfectant used and the bacterial microbial count on the specified dental environmental surfaces in the identified oral health facility.

\section{Acknowledgement}

Staff at the Catalysis and Peptide Research Unit (UKZN) for guidance and support in the laboratory component of this study. Adeola Shobo for his technical assistance with the MALDI-TOF machine.

\section{Declaration}

The authors declare no conflict of interest.

\section{Funding}

This paper forms part of a Masters dissertation for the first author. A scholarship of R25, 000.00 was obtained from the College of Health Sciences, UKZN.

\section{Lessons learned}

1. The protocols for infection control in the dental clinic needs to be reviewed.

2. The frequency of cleaning and the type of disinfectant used, needs to be reviewed.

3. Further research is required to identify other types of microbial activity on dental environmental surfaces.

4. Infection control procedures should be further emphasized in the undergraduate training programme.

5. Likewise, all members of the dental team (clinical and non-clinical staff) should have ongoing training in infection control.

\section{References}

1. Connor C. Cross-contamination control in prosthodontic practice. Int J Prosth. 1991; 4: 337-44.

2. Coleman DC, O'Donnell MJ, Shore AC, Russell RJ. Biofilm problems in dental unit water systems and its practical control. J Appl Microbiol. 2009; 106(5): 1424-37.

3. Petersen PE. Continuous improvement of oral health in the $21^{\text {st }}$ century-the approach of the WHO Global Oral Health Programme. 2003. 
4. Weinstein RA, Bridges CB, Kuehnert MJ, Hall CB. Transmission of Influenza: Implications for Control in Health Care Settings. Clin Infect Dis. 2003; 37(8): 1094-101.

5. Garner JS. Guideline for isolation precautions in hospitals. The Hospital Infection Control Practices Advisory Committee. Infect Control Hosp Epidemiol. 1996; 17(1): 53-80.

6. Kohn WG, Amy S, Collins AS, Cleveland JL, Harte JA., Eklund KL, Malvitz DM. Guidelines for Infection Control in Dental Health-Care Settings. 2003. December 19/52(RR17); 1-61. https://www.cdc.gov/mmwr/preview/mmwrhtml//rr5217 a1.htm.

7. Todd ECD. Microbiological safety standards and public health goals to reduce foodborne disease. Meat Sci. 2004; 66(1): 33-43.

8. Allsopp J, Basu MK, Browne RM, Burge PS, Matthews JB. Survey of the use of personal protective equipment and prevalence of work related symptoms among dental staff. Occup Environ Med. 1997; 54(2): 125-34.

9. Kümmerer K. Drugs in the environment: Emission of drugs, diagnostic aids and disinfectants into wastewater by hospitals in relation to other sources - A review. Chemosphere. 2001; 45(6-7): 957-69.

10. Todd ECD, Michaels BS, Holah J, Smith D, Greig JD, Bartleson CA. Outbreaks where food workers have been implicated in the spread of foodborne disease. Part 10. Alcohol-based antiseptics for hand disinfection and a comparison of their effectiveness with soaps. Journal of Food Protection, 2010; 73 (11): 2128 - 40

11. Bhalla A, Pultz NJ, Gries DM, Ray AJ, Eckstein EC, Aron DC, et al. Acquisition of Nosocomial Pathogens on Hands After Contact With Environmental Surfaces Near Hospitalized Patients. Infect Control Hosp Epidemiol. 2004; 25(2): 164-7.

12. Caveney L. Infection Control: The Surgical Environment and Ancillary Areas. In: Veterinary Infection Prevention and Control. John Wiley \& Sons, Inc. 2016; 245-72.

13. World Health Organization. Oral Health Surveys - Basic Methofd. $5^{\text {th }}$ ed. World Health Organization. 2013; 1-137.

14. Umar D, Basheer B, Husain A, Baroudi K, Ahamed F, Kumar A. Evaluation of bacterial contamination in a clinical environment. J Int Oral Health. 2015; 7(1): 53-5.

15. Kadaifciler DG, Cotuk A. Microbial contamination of dental unit waterlines and effect on quality of indoor air. Environ Monit Assess. 2014; 186(6): 3431-44

16. Kimmerle H, Wiedmann-Al-Ahmad M, Pelz K, Wittmer A, Hellwig E, Al-Ahmad A. Airborne microbes in different dental environments in comparison to a public area. Arch Oral Biol. 2012; 57(6): 689-96

17. Merchant VA. Herpesviruses and other microorganisms of concern in dentistry. Vol. 35, Dental Clinics of North America. 1991; 283-98.

18. Davies KJ, Herbert AM, Westmoreland D, Bagg J. Seroepidemiological study of respiratory virus infections among dental surgeons. Br Dent J. 1994; 176(7): 262-5.

19. Labandeira-Rey M, Couzon F, Boisset S, Brown EL, Bes M, Benito $Y$, et al. Staphylococcus aureus Panton-Valentine leukocidin causes necrotizing pneumonia. Science. 2007; 315(5815): 1130-3

20. Mehtar S, Shisana O, Mosala T, Dunbar R. Infection control practices in public dental care services: findings from one South African Province. J Hosp Infect. 2007; 66(1): 65-70.

21. Weinstein RA, Gaynes R, Edwards JR. Overview of Nosocomial Infections Caused by Gram-Negative Bacilli. Clin Infect Dis. 2005; 41(6): 848-54.

22. Molepo J, M Molaudzi M, Ralephenya TRMD. Microbial contaminants on dental bib chains with attached clips. SADJ 2015; 70(3): $104-7$.

23. Laheij AMGA, Kistler JO, Belibasakis GN, Välimaa H, de Soet JJ. Healthcare-associated viral and bacterial infections in dentistry. J Oral Microbiol. 2012; 4:1 17659. DOI: 10.3402/jom.v4i0.17659.
24. Kannan I, Jeevitha JY, Sambandam C, Jayalakshmi M, Premavathy RK, Shantha SInt S. Evaluation of surface contamination of bacteria in various dental clinics with special reference to obligate and facultative anaerobic spore bearing bacilli. J Med Res Health. 2014; 3: 554-9.

25. de Almeida CMF, de Carvalho AS, Duarte DA. Avaliação dos métodos de desinfecção de alicates ortodônticos. Dental Press J Orthod. 2012; 17(4): 105-9.

26. Fisher K, Phillips CA. The effect of lemon, orange and bergamot essential oils and their components on the survival of Campylobacter jejuni, Escherichia coli O157, Listeria monocytogenes, Bacillus cereus and Staphylococcus aureus in vitro and in food systems. J Appl Microbiol. 2006; 101(6): 1232-40.

27. Widmer AF. Replace Hand Washing with Use of a Waterless Alcohol Hand Rub? Weinstein A, editor. Clin Infect Dis. 2000; 31(1): 136-43.

28. Ribeiro MM, Neumann VA, Padoveze MC, Graziano KU. Efficacy and effectiveness of alcohol in the disinfection of semiritical materials: a systematic review. Rev Lat Am Enfermagem. 2015; 23(4): 741-52. DOI: 10.1590/0104-1169.0266.2611.

29. Lantagne D, Wolfe M, Gallandat K, Opryszko M. Determining the Efficacy, Safety and Suitability of Disinfectants to Prevent Emerging Infectious Disease Transmission. Water 2018; 10(10): 1397.

30. Angelillo IF, Bianco A, Nobile CGA, Pavia M. Evaluation of the efficacy of glutaraldehyde and peroxygen for disinfection of dental instruments. Letters in Applied Microbiol 1998; 27 : 292-6.

31. Castiglia P, Liguori G, Montagna MT, Napoli C, Pasquarella C, Bergomi $\mathrm{M}$, et al. Italian multicenter study on infection hazards during dental practice: Control of environmental microbial contamination in public dental surgeries. BMC Public Health. 2008; 8.

32. Turista DDR, Puspitasari E. The growth of Staphylococcus aureus in the blood agar plate media of sheep blood and human blood groups $\mathrm{A}, \mathrm{B}, \mathrm{AB}$, and $\mathrm{O}$. Jurnal Teknologi Laboratorium. 2019, 8(1): 1-7. DOl: 10.29238/teknolabjournal.v8i1.155 